\title{
Identification of Larvae and Recognition of New Synonymy for Two Chinese Onycholyda Sawflies (Insecta: Hymenoptera: Pamphiliidae) based on Molecular Data
}

\author{
Akihiko Shinohara ${ }^{1,4}$, Takuya Kiyoshi ${ }^{1},{\text { Meicai } \mathrm{Wei}^{2} \text {, and Yuichi Kameda }}^{3}$ \\ ${ }^{1}$ Department of Zoology, National Museum of Nature and Science, \\ 4-1-1 Amakubo, Tsukuba, Ibaraki 305-0005, Japan \\ E-mail: shinohar@kahaku.go.jp \\ ${ }^{2}$ Laboratory of Insect Systematics and Evolutionary Biology, Central South University of Forestry and Technology, \\ Changsha, 410004 China \\ ${ }^{3}$ Center for Molecular Biodiversity Research, National Museum of Nature and Science, \\ 4-1-1 Amakubo, Tsukuba, Ibaraki 305-0005, Japan \\ ${ }^{4}$ Corresponding author
}

(Received 16 November 2017; Accepted 15 January 2018)

\begin{abstract}
A molecular analysis based on mitochondrial COI+tRNA(Leu)+COII gene sequences has shown that unidentified larvae collected in Hunan, Hubei and Sichuan Provinces, China, belong to Onycholyda flavicostalis Shinohara, 2012, and O. sichuanica Shinohara, Naito and Huang, 1988 (Hymenoptera: Pamphiliidae), and that the latter species is conspecific with O. fanjingshanica Jiang, Wei and Zhu, 2004. Onycholyda fanjingshanica is thus synonymized with O. sichuanica. The first host plant records are Rubus adenophorus Rolfe (Rosaceae) for O. flavicostalis and Rubus spp. for O. sichuanica. The larvae of O. flavicostalis and O. sichuanica are briefly described and O. flavicostalis is newly recorded from Hubei and Sichuan Provinces.
\end{abstract}

Key Words: Hymenoptera, Pamphiliidae, Onycholyda, molecular analysis, larva, host plant, Rubus, new synonymy, China.

\section{Introduction}

Holometabolous insects exhibit conspicuous morphological differences between larval and imaginal stages and often between sexes. Identification of previously unknown larvae solely based on morphology is therefore usually impossible and conspicuous sexual dimorphism often causes publication of different names for different sexes of the same species, thus bringing confusion into classification. The only reliable conventional method for solving these problems is to obtain firm evidence for direct relationships between larvae and adults or between different sexes of adults by rearing, which is usually difficult and time-consuming. Recent developments of molecular methods make it much easier. Direct comparison of DNA molecules provides most useful tools for establishing such relationships (Caterino and Tishechkin 2006; Ahrens et al. 2007) and such molecular techniques have been applied also to some sawfly groups (Shinohara et al. 2016a, b, 2017).

Leaf-rolling sawflies of the Onycholyda wongi complex show large sexual dimorphism. This is one of the two species complexes of the O. wongi subgroup of the O. luteicornis group and is characterized by the roundly swollen upper frons in the female, the bidentate left mandible and the long 3rd antennomere (Shinohara 2002). It is represented by eight species mainly distributed in southern China. Of these, both sexes are known for O. odaesana Shinohara and
Byun, 1993, and O. flavicostalis Shinohara, 2012, whereas only the male is known for O. sichuanica Shinohara, Naito and Huang, 1988, and only the female is known for each of the five remaining species, including $O$. fanjingshanica Jiang, Wei and Zhu, 2004 (Shinohara and Wei 2012). Shinohara and Wei (2012) suggested a high possibility that O. sichuan$i c a$ and $O$. fanjingshanica are conspecific, the two taxa being the opposite sexes of one and the same species. Of the eight species of the $O$. wongi complex, immature stages and host plants are known only for O. odaesana (Shinohara and Wei 2010).

In 2009-2015, Shinohara obtained adult specimens of $O$. odaesana, O. flavicostalis, O. sichuanica and O. fanjingshani$c a$, as well as unidentified larvae presumably of Onycholyda species feeding on Rubus spp. (Rosaceae), including Rubus adenophorus Rolfe, in Hunan, Hubei and Sichuan Provinces, China. Here we present a result of our attempt to determine the specific relationships of $O$. sichuanica and O. fanjingshanica and to identify the unidentified larvae by using molecular methods.

\section{Materials and Methods}

Sampling. We examined 12 adult individuals of Onycholyda determined as O. flavicostalis, O. odaesana, O. sichuanica and O. fanjingshanica and 17 unidentified larvae presumably of Onycholyda collected in Hunan, Hubei and 
Sichuan Provinces, China (Table 1). Two male adult specimens of Pamphilius atricaudatus Shinohara, 2012, were used as the outgroup. The genera Onycholyda and Pamphilius belong to the tribe Pamphiliini, which is considered monophyletic (Shinohara 2002). The intergeneric relationships within the tribe are not well resolved, though Onycholyda is evidently a monophyletic group with a sister relationship with Pamphilius or its component subgroup (Shinohara 2002). Pamphilius atricaudatus belongs to the komonensis subgroup of the alternans group, which is a part of the large assemblage of ten species groups and this is a possible sister group of Onycholyda (Shinohara 2002). Pamphilius atricaudatus is thus well qualified as an outgroup species for the present analysis. Shinohara identified all the adult specimens based on published papers (Shinohara et al. 1988; Shinohara and Byun 1993; Jiang et al. 2004; Shinohara and Wei 2012) and examination of the relevant type material. All the materials are kept in the National Museum of Nature and Science, Tsukuba.

DNA extraction, PCR and Sequencing. Adults and larvae collected in the field for DNA analysis were preserved in $99 \%$ ethanol and kept in a fridge. Genomic DNA was extracted from middle legs of adults or anterior part of larval abdomen using NucleoSpin Tissue (MACHEREYNAGEL) following standard protocol. Polymerase chain reaction (PCR) was used to amplify a sequence of about 1300 base pairs that is combination of partial cytochrome $c$ oxidase subunit I (COI) gene (733 bp), complete tRNA Leucine (67-69 bp) and partial cytochrome $c$ oxidase subunit II (COII) gene $(461 \mathrm{bp})$ from total DNA template using two newly designed primers, HymenoF2 (5'-ACC AGG ATT TGG TAT AAT TTC TCA-3') and HymenoR1 (5'-CGA CCA GGG ATA GCA TCA AT-3'). PCR condition was: initial denaturation for $2 \mathrm{~min}$ at $94^{\circ} \mathrm{C}$, followed by 30 cycles of $10 \mathrm{~s}$ at $98^{\circ} \mathrm{C}, 15 \mathrm{~s}$ at $60^{\circ} \mathrm{C}$, and $1 \mathrm{~min}$ at $72^{\circ} \mathrm{C}$, with a final extension for $10 \mathrm{~min}$ at $72^{\circ} \mathrm{C}$. Reactions were aided by ExTaq HS polymerase (TaKaRa) and Tks Gflex DNA Polymerase (TaKaRa), and the products were purified with Exo-SAP-IT (Affymetrix). Sequencing reaction was performed using an ABI PRISM Dye Terminator Cycle Sequencing Ready Reaction Kit (Life Technologies) and electrophoresed on an ABI 3500xl sequencer (Life Technologies). The obtained sequences have been deposited in the DDBJ/EMBL/GenBank database under accession numbers given in Table 1.

Phylogenetic analysis. DNA sequences were aligned using MUSCLE implemented in MEGA7 (Edgar 2004; Kumar et al. 2016) with the initial setting. Phylogenetic trees were obtained by maximum parsimony (MP) and maximum likelihood (ML) methods implemented in MEGA. For MP analyses, heuristic searches were conducted with 10

Table 1. Material used for molecular analysis. All collected by A. Shinohara.

\begin{tabular}{|c|c|c|c|c|}
\hline \multicolumn{2}{|c|}{ sample no. } & collection data & \multicolumn{2}{|l|}{ GenBank } \\
\hline 765 & $\hat{\sigma}$ & HUNAN, Mt. Yunshan, 14. IV. 2012 & LC360118 & \multirow{4}{*}{ Onycholyda flavicostalis } \\
\hline 766 & $\hat{\sigma}$ & HUNAN, Mt. Yunshan, 9. IV. 2012 & LC360119 & \\
\hline 767 & q & HUNAN, Mt. Yunshan, 14. IV. 2010 & LC360120 & \\
\hline 778 & q & HUNAN, Mt. Yunshan, 10. IV. 2012 & LC360123 & \\
\hline 466 & larva & HUBEI, Muyu, Shennongjia, 18, V. 2010, on Rubus adenophorus, fixed 21. V. & LC360113 & \multirow{7}{*}{ Onycholyda flavicostalis** } \\
\hline $470-472$ & larva & HUBEI, Muyu, Shennongjia, 18, V. 2010, on Rubus adenophorus, fixed 22. V. & LC360114-LC360116 & \\
\hline 587 & larva & $\begin{array}{l}\text { SICHUAN, Mt. Emeishan, about } 32 \mathrm{~km} \text { from Baoguosi, 14. V. 2015, on Rubus } \\
\text { sp., fixed 18. V. }\end{array}$ & LC360117 & \\
\hline 775 & larva & $\begin{array}{l}\text { HUBEI, Qianjiaping, Shennongjia, 18, V. 2012, on Rubus adenophorus, fixed } \\
\text { 22. V. (AS120518A) }\end{array}$ & LC360121 & \\
\hline 777 & larva & $\begin{array}{l}\text { HUBEI, Qianjiaping, Shennongjia, 18, V. 2012, on Rubus adenophorus, fixed } \\
\text { 22. V. (AS120518B) }\end{array}$ & LC360122 & \\
\hline 781 & larva & $\begin{array}{l}\text { HUBEI, Guanmenshan, Shennongjia, 23, V. 2012, on Rubus adenophorus, } \\
\text { fixed 22. V. (AS120523) }\end{array}$ & LC360124 & \\
\hline $783-785$ & larva & $\begin{array}{l}\text { HUNAN, Mt. Yunshan, 2. V. 2009, on Rubus adenophorus, fixed 8. V. } \\
\quad \text { (AS090502C) }\end{array}$ & LC360125-LC360127 & \\
\hline 763 & $\hat{\sigma}$ & HUNAN, Mt. Yunshan, 10. IV. 2012 & LC360134 & \multirow{2}{*}{ Onycholyda sichuanica } \\
\hline 764 & $\hat{\sigma}$ & HUNAN, Mt. Yunshan, 16. IV. 2012 & LC360135 & \\
\hline 779,780 & q & HUNAN, Mt. Yunshan, 10. IV. 2012 & LC360136 LC360137 & Onycholyda sichuanica* \\
\hline 480,488 & larva & HUNAN, Mt. Hupingshan, 8. VI. 2013, on Rubus sp., matured \& fixed 11. VI. & LC360128 LC360132 & \multirow{4}{*}{ Onycholyda sichuanica** } \\
\hline 481,482 & larva & HUNAN, Mt. Hupingshan, 8. VI. 2013, on Rubus sp., matured \& fixed 10. VI. & LC360129 LC360130 & \\
\hline 486 & larva & HUNAN, Mt. Hupingshan, 8. VI. 2013, on Rubus sp., matured \& fixed 12. VI. & LC360131 & \\
\hline 489 & larva & HUNAN, Mt. Hupingshan, 8. VI. 2013, on Rubus sp., matured \& fixed 9. VI. & LC360133 & \\
\hline 768 & q & HUNAN, Mt. Yunshan, 10. IV. 2012 & LC360138 & \multirow{3}{*}{ Onycholyda odaesana } \\
\hline 771 & $\hat{\sigma}$ & HUNAN, Mt. Yunshan, 10. IV. 2012 & LC360139 & \\
\hline 772,773 & $\hat{\sigma}$ & HUNAN, Mt. Yunshan, 20. IV. 2010 & LC360140 LC360141 & \\
\hline 786,787 & $\hat{\sigma}$ & HUNAN, Mt. Yunshan, 19-20. IV. 2012 & LC360142 LC360143 & Pamphilius atricaudatus \\
\hline
\end{tabular}

*Originally identified as Onycholyda fanjingshanica. **Identified by molecular data. 
random addition analyses using equal character weights and tree-bisection-reconnection (TBR) branch swapping. Prior to ML analysis, we determined an appropriate model of sequence evolution and model parameters using MEGA. As a result, T92+I + G model was selected. Based on the selected model, ML analysis was performed with heuristic searches with subtree-pruning-regrafting-extensive (SPR) branch swapping. Nodal support for the MP and ML analyses were assessed using bootstrap analyses with 1000 replications.

Observations of morphology, plant scientific names, morphological terminology and photography. Observations of morphology were made with an Olympus SZ60 stereo binocular microscope. For the scientific names of the host plant and larval morphological terminology, we followed Lu and Boufford (2003) and Viitasaari (2002), respectively. Photographs were taken with digital cameras, Canon EOS Kiss Digital X and Ricoh Caplio GX100 (Figs 2, 3). The digital images were processed and arranged with Adobe Photoshop Elements ${ }^{\circledR} 9$ and 12 software.

\section{Results and Discussion}

Phylogenetic analysis. The MP analysis resulted in eight most parsimonious trees (144 steps, consistency index excluding uninformative sites $[\mathrm{CI}]=0.8951$, retention index $[\mathrm{RI}]=0.9743$ ). The result of ML and MP analyses were consistent with the relatively well-supported clades (Fig. 1). Both analyses classified Onycholyda specimens into three clades $(\mathrm{A}-\mathrm{C})$. Haplotype sources of each clade are as follows: clade A from O. flavicostalis and 11 undetermined larval samples, clade B from O. sichuanica, O. fanjingshanica and six undetermined larval samples, and clade $\mathrm{C}$ only from O. odaesana. Clades A and B were reconstructed as the reciprocal monophyly but the support value was rather low. Each of the clades A and B was supported by high bootstrap values (99\%) and the internal distance (maximum composite likelihood model) of each of the two clades was very small $(0.5 \%$ in clade $A$ and $0.3 \%$ in clade $B)$, which was comparable to the intraspecific distance in O. odaesana $(0.5 \%$, clade $\mathrm{C})$. The distances between clades $\mathrm{A}$ and $\mathrm{B}, \mathrm{B}$ and $C$, and $C$ and $A$ were $3.4-3.7 \%, 3.2-3.6 \%$, and 3.2-3.7\%, respectively, and the distance between Onycholyda spp. and outgroup was $8.8-9.5 \%$. This strongly suggests that O. sichuanica and O. fanjingshanica (both in clade B) are conspecific and that the undetermined larval samples in clade A belong to $O$. flavicostalis and those in clade B belong to $O$. sichuanica/O. fanjingshanica.

Onycholyda flavicostalis Shinohara, 2012 (Fig. 2)

Onycholyda flavicostalis Shinohara, in Shinohara and Wei, 2012: 57.

Distribution. China (Shaanxi, Hubei, Hunan, Sichuan).

Host plants. Rubus adenophorus Rolfe., Rubus sp.

Field observations and rearing records. Case A. One leaf-roll on Rubus adenophorus containing seven gregari-

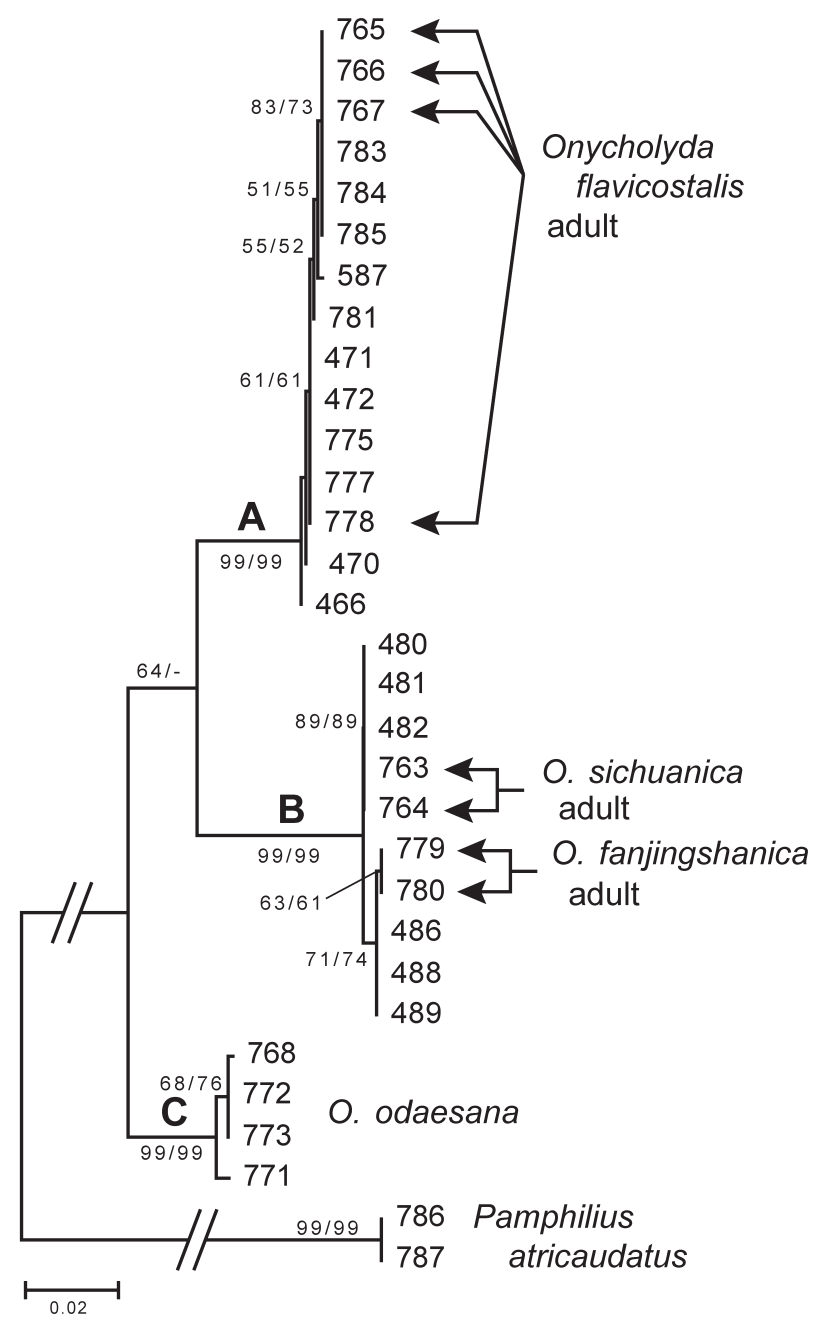

Fig. 1. The maximum likelihood tree based on $1184 \mathrm{bp}$ of mitochondrial COI+tRNA(Leu)+COII gene sequence (-ln likelihood $=2213.6646)$. Numbers on branches indicate bootstrap values for MP/ML analyses (shown only for higher nodes with $>50$ ). Each terminal label represents the sample number.

ous middle-instar larvae was found in Mt. Yunshan, Hunan Province on May 2, 2009. The leaf-roll was on the underside of the leaf and remains of the egg shell were not found. The larvae were fixed on May 8 (including sample nos. 783-785, Table 1). Case B. Nine leaf-rolls, one each containing one larva, were found on $R$. adenophorus at Yaolangou, Muyu, Shennongjia, Hubei Province, on May 18, 2010. All the nine larvae were fixed in ethanol on May 19 and 21 (one of them, sample no. 466). Another leaf-roll containing three larvae was also found on $R$. adenophorus at the same locality on the same day. The three larvae were fixed in ethanol on May 22 (sample nos. 470-472). For all the ten leaf-rolls examined, remains of the egg shells were not found. Case $C$. Two leaf-rolls were found on $R$. adenophorus in Qianjiaping, Shennongjia, Hubei Province on May 18, 2012. One of them (Fig. 2A) contained one larva and the other (Fig. 2B) contained two larvae. Each of the leaf-rolls was on the underside of the leaf and remains of the egg shell were not found. The larvae matured (one of them in Fig. 2C) and were fixed on May 22 (including sample nos. 775, 777). Case D. Two 


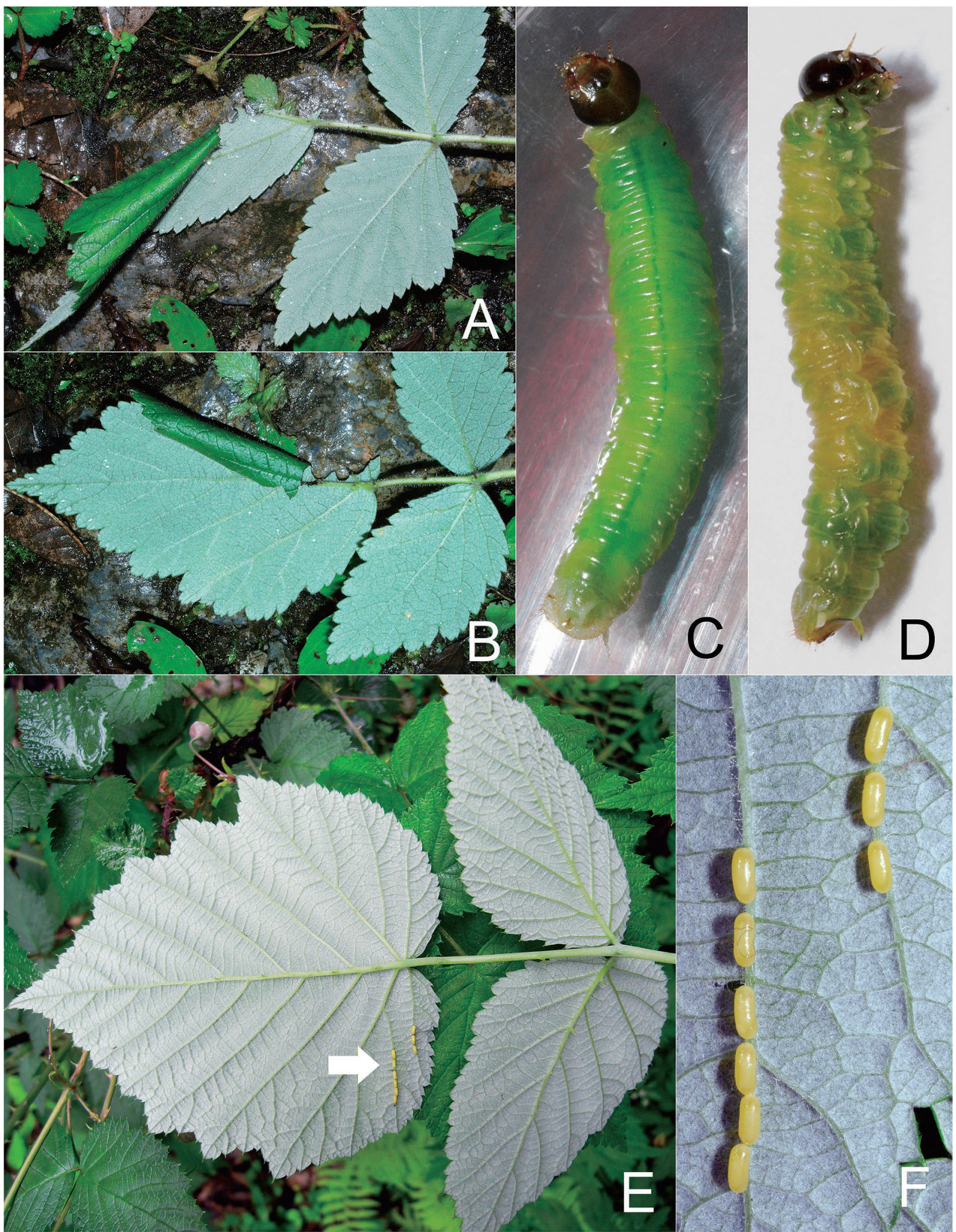

Fig. 2. Onycholyda flavicostalis, larval leaf-rolls (A, B), mature larva (C, D), and eggs deposited on the leaf of Rubus adenophorus (E, F), all collected at Shennongjia, Hubei Province, and photographed at the site (A, B, E, F) or indoors (C, D) by A. Shinohara. - A, Leaf-roll (one larva, sample no. 775 inside), Qianjiaping, May 18, 2012; B, leaf-roll (two larvae, including sample no. 777 inside), Qianjiaping, May 18, 2012; C, mature larva (sample no. 775), May 22, 2012; D, mature larva (sample no. 781 from one of the eggs shown in E), June 6, 2012; E, leaves with two groups of eggs (arrowed), Guanmenshan, May 23, 2012; F, same, enlarged.

groups of eggs, consisting of five eggs and three eggs, respectively, were found on the same leaf of $R$. adenophorus in Guanmenshan, Shennongjia, Hubei Province on May 23,
2012. The groups of eggs were deposited on the lateral veins in a line in the basal part of the underside of a leaf (Fig. 2E, F). The eggs hatched on May 27 and the larvae were fixed on 

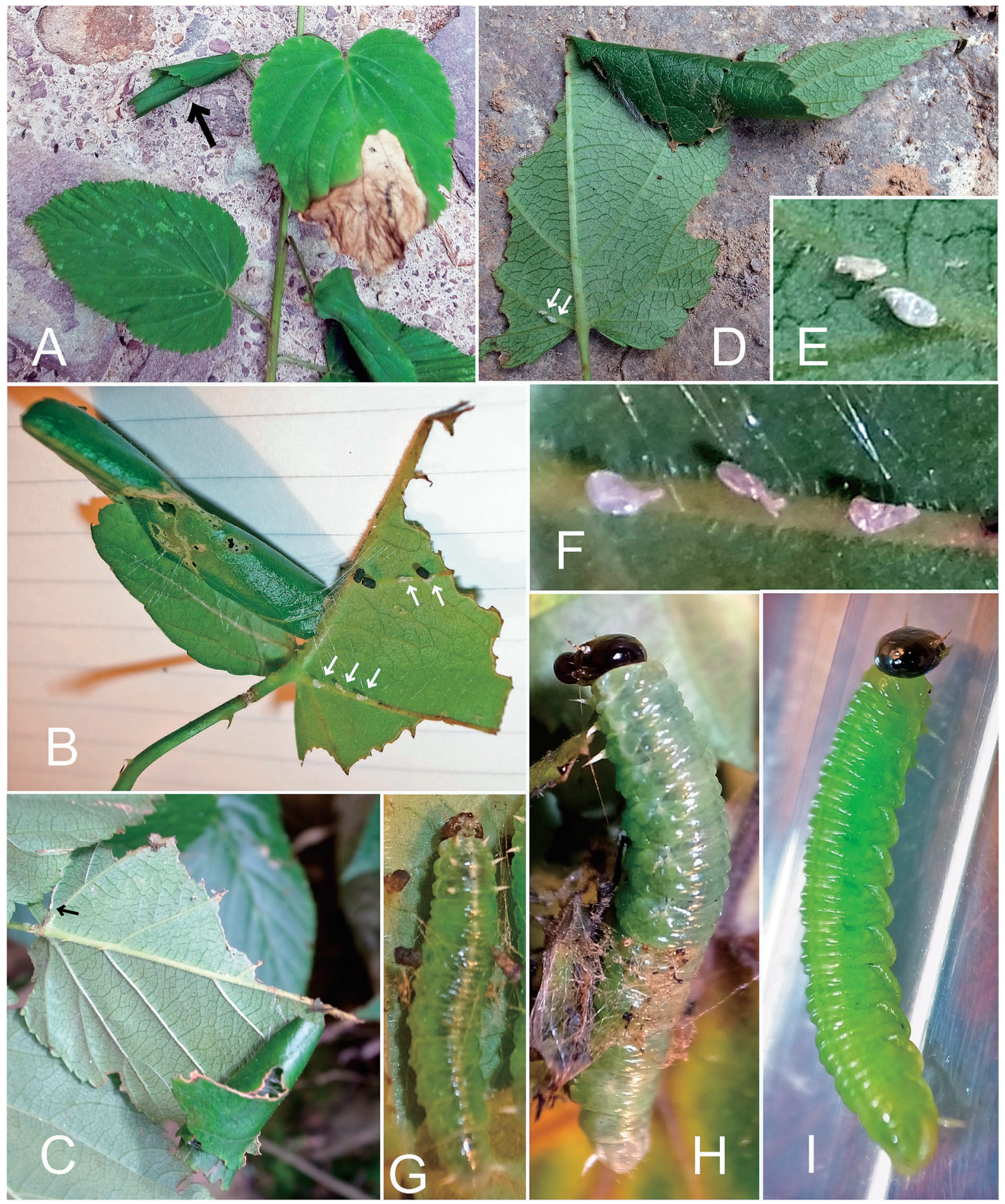

Fig. 3. Onycholyda sichuanica, larval leaf-rolls (A-D), remains of egg shells (D, E) and late instar and mature larvae (G-I), all collected at Mt. Hupingshan, Hunan Province, June 8, 2013 and photographed at the site (A, C, D) or indoors (B, E-I) by A. Shinohara. -A, Leaf-roll on Rubus sp. (arrowed); B, leaf-roll on Rubus sp.; C, leaf-roll on Rubus sp.; D, leaf-roll on Rubus sp.; E, close-up of two egg shells, same as in D; F, close-up of three egg shells, same as in B; G, late instar larva, June 14; H, late instar larva, June 14; I, mature larva, June 9 (sample no. 489). Remains of egg shells arrowed in B-D.

June 6 (one of them sample no. 781). Case E. One leaf-roll containing one larva was found on Rubus sp. along a narrow unpaved car road at about $1600 \mathrm{~m}$ in altitude about $32 \mathrm{~km}$ from Baoguosi on Mt. Emeishan, Sichuan Province, on May 14, 2015. The larva was fixed in ethanol on May 18 (sample no. 587).
Egg. Normal for pamphiliids, yellowish white, deposited in a row along lateral veins in basal part of the leaf (Fig. 2E, F).

Larva. Mature larva (Fig. 2C, D). Head black, with epicranial suture and part of clypeus greenish; antenna creamy white, each antennomere more or less dark brown- 
ish; labrum and mandible dark brown, palpi pale brown, and other mouthparts greenish, partly marked with blackish brown; trunk pale greenish, terminal segment largely creamy white; cervical sclerite partly blackish; thoracic legs and subanal appendage greenish white; suranal hook dark brown.

Remarks. Our molecular analysis has clearly shown that the larvae feeding on Rubus adenophorus from Shennongjia, Hubei Province, and Mt. Yunshan, Hunan Province, and those feeding on Rubus sp. from Mt. Emeishan, Sichuan Province, belong to O. flavicostalis, which was described from Mt. Yunshan, Hunan Province. This is the first record of the host plant and larva of $O$. flavicostalis and the first distribution record of this sawfly from Hubei and Sichuan Provinces.

Onycholyda flavicostalis and O. odaesana Shinohara and Byun, 1993, occur together on Mt. Yunshan in Hunan Province (Shinohara and Wei 2012) and the larvae of the two species feed on the same host plant, $R$. adenophorus (Shinohara and Wei 2010; present study). The larva of O. flavicostalis is a gregarious or solitary leaf-roller with a black head, whereas the larva of $O$. odaesana is solitary and has a pale brown head with three black spots. Among the non-Chinese species, the larva of O. esakii (Takeuchi, 1938) from Japan is a gregarious leaf-roller and has a color pattern very similar to that of O. flavicostalis (Shinohara and Kojima 2009). We are not able to distinguish the larvae of the two species based on a current knowledge besides the differences in distribution and the host plant species. The mature larva of $O$. sichuanica also has an entirely black head and a pale green trunk but the cervical sclerite is entirely pale in this species, unlike those of O. flavicostalis and O. esakii.

As noted in the section of field observations above, the female of $O$. flavicostalis deposits eggs in a row (up to seven eggs together) and the middle-instar larvae live gregariously in one leaf-roll, whereas the late-instar larvae may live in a small group or even solitarily. The range of variation in the larval gregariousness of this species should be confirmed by obtaining further information.

Onycholyda sichuanica Shinohara, Naito and Huang, 1988 (Fig. 3)

Onycholyda sichuanica Shinohara, Naito and Huang, 1988: 92; Xin and Wu, 2010: 10; Shinohara and Wei, 2012: 56.

Onycholyda fanjingshanica Jiang, Wei and Zhu, 2004: 44; Shinohara and Wei, 2012: 56. N. syn.

Distribution. China (Sichuan, Gansu, Guizhou, Guangxi, Hubei, Hunan, Anhui, Fujian).

Host plants. Rubus spp.

Field observations and rearing records. On June 8, 2013, Shinohara found seven leaf-rolls (four of them in Fig. 3A-D), containing ten larvae, on Rubus spp. at Huatai, ca. $900 \mathrm{~m}$, Mt. Hupingshan, Hunan Province. Of the seven leaf-rolls, one contained three larvae (three egg shells), one contained two larvae (one of them sample no. 486, two egg shells, Fig. 3D, E), while the other five contained one larva, respectively (sample nos. 480-482, 488, 489; for four of them, no egg shells were found, whereas five egg shells were found on the remaining one leaf, Fig. 3B, F). Of the ten larvae, one larva (sample no. 489) matured and was fixed in ethanol on June 9, two (sample nos. 481, 482) on June 10, two (sample nos. 480,488 ) on June 11 , one (sample no. 486 ) on June 12, while the remaining four were fixed in ethanol on June 14 before maturation. Six of the ten larvae were used for molecular analysis (Table 1).

All the leaf-rolls and remains of the egg shells were found on the under surface of the leaves and all the egg shells were located on the lateral veins near the base of the leaf (Fig. 3B-F). The larval abodes were irregular in shape (Fig. $3 \mathrm{~A}-\mathrm{D})$.

Larva. Late instar (Fig. 3G, H): Head black; antenna creamy white, each antennomere more or less dark brownish; trunk pale greenish white, terminal segment largely creamy white; thoracic legs and subanal appendage white. Mature larva (Fig. 3I): Similar to the preceding, but antenna pale brown and trunk, including thoracic legs and subanal appendage, vivid pale green.

Remarks. Shinohara and Wei (2012) suspected that $O$. sichuanica (only males known) and O. fanjingshanica (only females known) are opposite sexes of the same species, because the two "species" had much in common in morphology and were obtained together in the same area on Mt. Yunshan, Hunan Province. Our analysis based on mitochondrial $\mathrm{COI}+\mathrm{tRNA}(\mathrm{Leu})+\mathrm{COII}$ gene sequences perfectly supported the hypothesis that the two taxa are conspecific, and we hereby propose to treat them as synonyms.

The adult specimens from Mt. Yunshan (sample nos. $763,764,779,780)$ and larval material from Mt. Hupingshan (sample nos. 480-482, 486, 488, 489), both localities in Hunan Province, agreed in mitochondrial $\mathrm{COI}+\mathrm{tRNA}(\mathrm{Leu})+\mathrm{COII}$ gene sequences and we determine the larvae as O. sichuanica. This is the first record of the larvae and host plant of this sawfly.

The previously unknown larva of this species is well characterized by the entirely black head and entirely pale green trunk in late-instar and prepupal stages (Fig. 3G-I). It is quite similar to that of $O$. flavicostalis except for the entirely pale cervical sclerite (compare Fig. 3G-I with Fig. 2D). The larva of the Japanese $O$. esakii also has a similar color pattern, but the cervical sclerite is black (Shinohara and Kojima 2009). The observed larvae of O. sichuanica were solitary or living together in a small group.

\section{Acknowledgments}

We thank X.-L. Yu (Central South University of Forestry and Technology, Changsha) for his identification of the host plants and D. R. Smith (U.S. Department of Agriculture, Washington, D.C.) and an anonymous reviewer for their helpful comments on the manuscript. Shinohara thanks H.-Y. Nie, W. Xiao and the former students of Wei (Central South University of Forestry and Technology, Changsha) and Z.-J. Li (Lishui Academy of Forestry, Lishui) for their 
great assistance during the collecting trips. This study was partly supported by JSPS KAKENHI Grant No. 25440223.

\section{References}

Ahrens, D., Monaghan, M. T., and Vogler, A. P. 2007. DNA-based taxonomy for associating adults and larvae in multi-species assemblages of chafers (Coleoptera: Scarabaeidae). Molecular Phylogenetics and Evolution 44: 436-449.

Caterino, M. S. and Tishechkin, A. K. 2006. DNA identification and morphological description of the first confirmed larvae of Hetaeriinae (Coleoptera: Histeridae). Systematic Entomology 31: 405418.

Edgar, R. C. 2004. MUSCLE: multiple sequence alignment with high accuracy and high throughput. Nucleic Acids Research 32: 17921797.

Jiang, J.-G., Wei, M.-C., and Zhu, X. 2004. Two new species of Pamphiliidae from China (Hymenoptera: Pamphiliidae). Journal of Central South Forestry University, Zhuzhou 24(2): 44-46.

Kumar, S., Stecher, G., and Tamura, K. 2016. MEGA7: Molecular Evolutionary Genetics Analysis Version 7.0 for bigger datasets. Molecular Biology and Evolution 30: 2725-2729.

Lu, L.-D. and Boufford, D. E. 2003. 28. Rubus Linnaeus, Sp. P1. 1: 492. 1753. Pp. 195-285. In: Wu, Z. Y., Raven, P. H., and Hong, D. Y. (Eds) Flora of China 9. Science Press, Beijing, and Missouri Botanical Garden Press, St. Louis.

Shinohara, A. 2002. Systematics of the leaf-rolling or webspinning sawfly subfamily Pamphiliinae (Hymenoptera): a preliminary overview. Pp. 359-438. In: Viitasaari, M. (Ed.) Sawflies (Hymenoptera, Symphyta) I. Tremex Press, Helsinki.

Shinohara, A. and Byun, B.-K. 1993. Pamphiliid sawfly genera Neurotoma and Onycholyda (Hymenoptera, Symphyta) of Korea. Insecta Koreana 10: 75-91.
Shinohara, A., Hara, H., Kramp, K., Blank, S. M., and Kameda, Y. 2017. Bird droppings on chestnut leaves or sawfly larvae? DNA barcodes verify the occurrence of the archaic Megaxyela togashii (Hymenoptera, Xyelidae) in Hokkaido, Japan. Zootaxa 4221: 220-232.

Shinohara, A., Kameda, Y., Ibuki, S., Kiyoshi, T., Kakuda, T., and Kojima, H. 2016a. Pamphilius ishikawai feeds on Astilbe: the first record of Pamphiliidae (Hymenoptera) associated with Saxifragaceae. Zootaxa 4098: 167-178.

Shinohara, A., Kiyoshi, T., and Kameda, Y. 2016b. New distribution records of two species of Arge and Spinarge (Hymenoptera, Argidae) from Kyushu, Japan. Bulletin of the National Museum of Nature and Science, Tokyo, Series A 42: 81-85.

Shinohara, A. and Kojima, H. 2009. Host plants and larvae of three species of the sawfly genus Onycholyda (Insecta, Hymenoptera, Pamphiliidae) in Japan. Bulletin of the National Museum and Nature and Science, Tokyo, Series A 35: 103-111.

Shinohara, A., Naito, T., and Huang, F.-S. 1988. Pamphiliid sawflies (Hymenoptera) from Xizang (Tibet) and Sichuan, China. Annales de la Société Entomologique de France, (N.S.) 24: 89-97.

Shinohara, A. and Wei, M.-C. 2010. Discovery of host plant and larva of Onycholyda odaesana (Hymenoptera, Pamphiliidae) in Hunan Province, China. Japanese Journal of Systematic Entomology 16: 105-107.

Shinohara, A. and Wei, M.-C. 2012. Pamphiliid sawflies (Hymenoptera, Symphyta) of Mt. Yunshan, Hunan Province, China. Memoirs of the National Museum of Nature and Science, Tokyo (48): 53-74.

Viitasaari, M. 2002. The suborder Symphyta of the Hymenoptera. Pp. 11-174. In: Viitasaari, M. (Ed.) Sawflies (Hymenoptera, Symphyta) I. Tremex Press, Helsinki.

Xin, H. and $\mathrm{Wu}, \mathrm{X} .-\mathrm{Y}$. 2010. The investigation and taxonomical research of the sawflies [sic] species from Gansu Province II. A list of the genera and species (Hymenoptera: Pamphiliidae, Megalodontesidae). Journal of Gansu Forestry Science and Technology 35(1): 9-11. [In Chinese with English abstract] 